\title{
O Olhar que Olha o Outro... Um Estudo com Familiares de Pessoas em Quimioterapia Antineoplásica
}

\author{
Caring With a View Towards Others... \\ A Study of Family Members of Patients Undergoing Cancer Chemotherapy
}

Maria das Graças Gazel de Souza', Fátima Helena do Espírito Santo²

\section{Resumo}

Estudo de natureza qualitativa que objetiva descrever os sentimentos e reaçôes da família frente ao parente em quimioterapia antineoplásica, identificar as expectativas da família ao acompanhar o parente em quimioterapia antineoplásica e discutir as possibilidades de atuação do enfermeiro junto a essa família. A coleta de informaçôes envolveu observação simples e entrevistas semi-estruturadas com familiares de dez pessoas em tratamento de quimioterapia antineoplásica. Concluiu-se que a trajetória dessa família é permeada por momentos difíceis e que o câncer e seu tratamento envolvem não só o doente, mas todo o grupo familiar que se mantém sempre disposto a ajudar o parente no enfrentamento da doença. Assim, o cuidado do enfermeiro e da equipe multiprofissional é fundamental para proporcionar suporte ao cliente e à sua família visando à melhoria da qualidade de vida.

Palavras-chave: Neoplasias, Quimioterapia, Família, Cuidados de Enfermagem

${ }^{1}$ Enfermeira Residente do Instituto Nacional de Câncer (INCA)

${ }^{2} \operatorname{Profa}^{\mathrm{a}} \mathrm{Dr}^{\mathrm{a}}$ do Departamento de Enfermagem Médico-Cirúrgica da Universidade Federal Fluminense (UFF)

Endereço para correspondência: Maria das Graças Gazel de Souza . Rua Doutor Jarbas Marques, 120 - Além Paraíba - Minas Gerais (MG), Brasil CEP: 36660-000. E-mail: mariagazel@bol.com.br 


\section{INTRODUÇÃO}

O interesse em desenvolver este estudo surgiu a partir de experiências vivenciadas diante da doença de um familiar; da dor, das angústias, das expectativas após cada nova cirurgia e da desesperança frente a cada nova metástase, mas, principalmente, pelas transformaçōes percebidas em seu corpo no momento em que foi submetido ao tratamento de quimioterapia antineoplásica.

Atualmente, é sabido que é tão difícil para o paciente quanto para a família enfrentar o câncer, por se tratar de uma doença que ainda mexe muito com o imaginário das pessoas, fazendo com que o doente seja alvo de penúria de todos os que o cercam e por despertar em seus familiares "sentimentos e reações estressantes como frustração, ansiedade, raiva, vergonha, pesar e incerteza"1.

Tudo isso tende a ser mais evidente quando o tratamento quimioterápico é iniciado e a família passa a acompanhar de perto as repercussóes e os efeitos dos agentes antineoplásicos em seu parente. Por ser tratar de uma terapêutica sistêmica, a quimioterapia antineoplásica gera reaçôes desagradáveis no organismo do paciente, tais como: náuseas, vômitos, diarréia, queda de pêlos e ulcerações na mucosa oral. Todos esses efeitos afetam a aparência física do paciente, levando$o$, muitas vezes, a sentimentos de revolta frente a tal situação e à vergonha do próprio corpo.

Diante dessa situação, ao vivenciar a "experiência do câncer", a família enfrenta uma série de sentimentos angustiantes e dolorosos, lidando com o que chamamos de "experiência do adoecer em família", um momento tão difícil tanto para o paciente quanto para a família que passam, juntos, pelos mesmos sentimentos e experienciam o medo e a expectativa da morte, pois cuidar de pessoas que fazem tratamento quimioterápico traz dor e sofrimento, principalmente quando se trata de alguém muito próximo².

E quanto mais a família convive, participa e se envolve com a história do seu parente mais sofre ao assistir a progressão das espoliações que a doença e o tratamento causam no organismo e na imagem daquela pessoa ${ }^{3}$.

Nesse contexto, é também muito difícil para a família vivenciar todas as transformaçôes diante da doença de seu parente, que se torna fragilizado frente àqueles que o acompanham nessa etapa do seu tratamento. Pensando nisso, surgiu o interesse em estudar como é para a família ver os efeitos da quimioterapia no seu parente e o que o enfermeiro pode fazer para ajudar a família no enfrentamento desse tipo de situação. Essa realidade sensibiliza a todos diante da necessidade de humanizar a assistência de enfermagem aos familiares de pessoas em quimioterapia antineoplásica que também sofrem diante da doença e do seu tratamento.
A partir dessas reflexões, foi definido, como objeto de estudo, a família frente ao parente submetido à quimioterapia antineoplásica.

Considerando esse contexto, pôde-se nortear este estudo de acordo com as seguintes questôes: Como é para a família ver os efeitos da quimioterapia no seu parente e o que os enfermeiros podem fazer para ajudar a família no enfrentamento desse tipo de situação?

De acordo com a problemática descrita, foram traçados os seguintes objetivos: descrever os sentimentos e reaçōes da família frente ao parente em quimioterapia antineoplásica; identificar as expectativas da família ao acompanhar esse parente nesse tipo de tratamento; e discutir as possibilidades de atuação do enfermeiro junto à família do paciente em quimioterapia antineoplásica.

\section{A tRAJeTÓRIA METODOLÓGICA}

$\mathrm{O}$ estudo é de natureza qualitativa que, segundo Minayo (1994, p.22) ${ }^{4}$, "se preocupa com o universo de valores, crenças, afirmaçôes e significados envolvidos nas relações humanas e que não podem ser quantificadas em dados numéricos e análises estatísticas."

Por entender que o pesquisador não pode quantificar os sentimentos e expectativas vivenciadas pela família do doente submetido à quimioterapia antineoplásica, uma vez que, "a pesquisa qualitativa responde a questóes muito particulares, com um nível de realidade que não pode ser quantitativo" 5 , a escolha por tal metodologia pode ser justificada.

A pesquisa foi realizada no setor de quimioterapia do Hospital Universitário Antônio Pedro (HUAP) da Universidade Federal Fluminense (UFF) com dez familiares que estavam acompanhando um parente em tratamento de quimioterapia há no mínimo um mês, tempo considerado suficiente para o conhecimento do contexto terapêutico pelo qual o doente estava inserido.

\section{A COLETA DE INFORMAÇÕES}

Antes de iniciar esta etapa, um protocolo de pesquisa foi apresentado ao Comitê de Ética em Pesquisa (CEP) do Hospital Universitário Antônio Pedro, conforme preconizado na resolução no 196/96 do Conselho Nacional de Saúde sobre a realização de pesquisas envolvendo seres humanos. Após a aprovação, iniciouse a coleta de informações em duas etapas: fase exploratória com observação simples e fase de trabalho de campo com a realização das entrevistas semiestruturadas, que constavam das seguintes perguntas:

1) Quanto tempo está acompanhando o parente em quimioterapia antineoplásica?

2) Qual sua reação ao saber que seu parente seria submetido ao tratamento de quimioterapia antineoplásica? 
3) Quais as suas expectativas em relação ao tratamento de quimioterapia antineoplásica do seu parente?

4) O que você acha que o enfermeiro e demais profissionais da área de saúde podem fazer para ajudá-lo?

5) Como você se sente ao ver seu familiar em quimioterapia?

\section{Fase exploratória: a entrada no cenário}

Nessa fase, desenvolveu-se a observação simples que, segundo Minayo ${ }^{5}$, permite captar uma variedade de situações ou fenômenos que não são obtidos por meio de perguntas. As observaçôes tiveram como base o seguinte roteiro:

1) A chegada dos pacientes e seus familiares no setor: as expressões, os gestos, as conversas, forma de caminhar, condições físicas.

2) O setor de quimioterapia antineoplásica: horário de atendimento, estrutura física, condições de iluminação, limpeza, ventilação, lazer (tv, vídeo, músicas, revistas etc), acomodaçôes para os pacientes e família, condições dos suportes de soro, bomba infusora, poltronas, acondicionamento dos materiais, macas, posto de enfermagem etc.

3) Equipe de saúde: composição, escala, formas de comunicação, relacionamento interprofissional, relacionamento com pacientes e familiares.

4) $\mathrm{O}$ paciente em quimioterapia: atuação da equipe de enfermagem (forma de cuidar, intervençôes), condiçôes clínicas, complicações e reaçôes à quimioterapia.

5) Impressões do pesquisador.

Os registros foram realizados em um diário de campo, durante toda a estadia ali no setor de quimioterapia, perfazendo um total de 12 horas. A partir dessas observações, começou o processo de identificação dos sujeitos do estudo: familiares de pessoas que estavam fazendo tratamento de quimioterapia antineoplásica. Para isso, pôde-se contar com a ajuda dos enfermeiros do setor que, através de suas experiências e conhecimentos, indicavam quem eram os pacientes que costumavam chegar sempre acompanhados.

\section{Fase de trabalho de campo: as entrevistas}

As entrevistas foram realizadas no pátio do Hospital Universitário Antônio Pedro da Universidade Federal Fluminense, em frente ao setor de quimioterapia. Dez entrevistas foram gravadas em fitas magnéticas, com uma duração média de 40 minutos cada uma.

Durante as primeiras entrevistas, houve um pouco de dificuldade em explorar as falas dos sujeitos, no entanto, com o passar do tempo foi encontrada a melhor forma de fazer com que eles pudessem falar sobre o que sentiam, pensavam e sobre as experiências que estavam vivenciando.
Para isso, tentou-se, ao máximo, uma aproximação dos sujeitos para "quebrar" a barreira que separa, muitas vezes, o profissional do doente.

Além disso, o tempo de permanência dos profissionais de enfermagem naquele setor de quimioterapia, 6 meses, e o contato com essas pessoas foi suficiente para que se desenvolvesse um laço de amizade entre eles. Lá era possível ajudar os enfermeiros com o preparo das medicações, bem como com a assistência direta aos pacientes com câncer, e supõe-se que isso tenha feito com que as famílias adquirissem certa confiança e simpatia pelo entrevistador, o que favoreceu o desenvolvimento dessa pesquisa e a aproximação com os sujeitos do estudo.

As entrevistas foram realizadas com 10 familiares de pessoas em quimioterapia antineoplásica, sendo 7 pessoas do sexo feminino e 3 do sexo masculino, das quais, 6 eram casadas, 3 solteiras e 1 divorciada. Essas pessoas apresentavam entre 30 e 70 anos de idade. Quanto à ocupação: 4 trabalhavam em casa com o serviço doméstico, 1 era professor, 1 era médico, 1 era agente de saúde, 1 era empresário artístico, 1 estava desempregado e a outra era empregada doméstica. Em relação ao grau de parentesco: 4 eram filhos, 1 era neta, 2 eram esposas, 1 era marido, 1 era pai e 1 mãe. Destas pessoas, 6 tinham entre dois e cinco filhos e 4 não tinham filhos. Quanto ao local de moradia: 5 moravam em São Gonçalo, 1 em Itaipu, 2 em Niterói e 2 em Itaboraí.

\section{ORganização E TRATAMENTO das INFORMAÇ̃̃ES}

Após encerrar a coleta de informaçōes, chegou-se à etapa de organização das informaçôes, procedendo inicialmente à digitação dos registros do diário de campo. Em seguida, as fitas das entrevistas foram transcritas na sua totalidade para não perder a integridade das falas dos sujeitos e, após identificação com nomes fictícios, para preservar o anonimato dos sujeitos, foram digitadas.

\section{A ANÁLISE DAS INFORMAÇ̃̃ES}

Nessa etapa, foram realizadas diversas leituras das informações coletadas para identificação dos temas comuns que foram agrupados nas seguintes categorias: - O Tratamento Quimioterápico: A Notícia - inclui as falas relacionadas ao início do tratamento quimioterápico. - A Quimioterapia: Sentindo na Pele - inclui as falas relacionadas aos sentimentos da família frente ao parente em quimioterapia antineoplásica.

- A Quimioterapia e seus Horizontes - inclui as falas relacionadas às expectativas da família durante a quimioterapia. - O Cuidado que Acolhe o Outro - inclui as falas relacionadas às possibilidades de apoio da equipe multiprofissional ao familiar e ao paciente. 


\section{CONHECENDO A TEMÁTICA}

O impacto psicossocial das doenças crônicas como o câncer tem sido documentado e revisto em muitas pesquisas permitindo assim que as intervençōes de enfermagem sejam apropriadamente sustentadas com o objetivo de guiar a assistência ${ }^{6}$.

O Brasil classifica-se entre os países com maior incidência de câncer em todo o mundo. Os dados epidemiológicos indicam o câncer como um problema de saúde pública no Brasil. Fatores como o aumento na expectativa de vida, a industrialização, a urbanização e os avanços tecnológicos na área da saúde estão relacionados ao aumento do risco de desenvolvimento de câncer, além das mudanças nos hábitos de vida da população ${ }^{6}$.

Embora o câncer afete todas as faixas etárias, sua incidência é maior em pessoas com mais de 65 anos do sexo masculino. A sua maior suscetibilidade está relacionada, sobretudo, aos fatores extrínsecos, tais como: o ambiente, em particular a ocupação, dieta, estresse e hábitos de vida ${ }^{7}$. Trata-se, assim, de uma doença complexa, que pode ser de longa duração e que compromete significativamente a vida dos indivíduos nas dimensões biológica, social e afetiva, exigindo assistência especializada de diferentes profissionais ${ }^{8}$.

A quimioterapia antineoplásica representa um avanço na cura e controle do câncer, aumentando a expectativa de vida do paciente. É essencial, no entanto, que os profissionais de saúde que atuam na área de oncologia ofereçam suporte emocional, e efetivas orientações quanto aos objetivos e efeitos colaterais do tratamento quimioterápico?.

É fundamental que, além do seu papel técnico relacionado ao manuseio das drogas, os enfermeiros atuem como multiplicadores de informaçôes corretas a respeito do tratamento quimioterápico ${ }^{10}$.

Diante da agressividade do tratamento e do prognóstico incerto, a família do doente sente-se abatida, buscando apoio na equipe multidisciplinar e, principalmente, na enfermagem que presta assistência contínua ao paciente em tratamento quimioterápico. Para Smeltzer; Bare (2002),"[...] a enfermeira que lida com câncer deve estar preparada para apoiar o cliente e a família em todas as extensões das crises, seja física, emocional, social, cultural e espiritualmente ${ }^{7}$."

Portanto, cabe aos enfermeiros ajudar ao paciente e a sua família a enfrentar o impacto da quimioterapia, a agressividade de seus efeitos colaterais e tóxicos, permitindo a expressão de sentimentos, explicando e fornecendo informações a respeito da doença e da importância da continuidade do tratamento.

Os processos emocionais desencadeados nesses pacientes exigem um profissional especializado. É essencial compreender e dar suporte a essas transformaçōes, bem como ouvir e aprender com o paciente, tendo sempre em mente que se está cuidando de um ser humano e não apenas da enfermidade que ele traz ${ }^{11}$.

Diante de uma patologia como o câncer, sabe-se que o envolvimento familiar é inevitável. Mas o que é a família? A família é a principal instituição social em que o indivíduo inicia suas relações afetivas, cria vínculos e internaliza valores. Essa relação familiar apresenta-se de forma interligada como se fosse a extensão do outro, pois acreditase que a experiência de uma doença grave traz modificações no modo de pensar, sentir e agir das pessoas ${ }^{12}$.

A esse respeito, Pedrolo e Zago (2002) ${ }^{13}$ destacam que mudanças em um membro da família afetam todos os outros, bem como o sistema como um todo, pois ela é:

um grupo social delimitado e identificável, cujas dinâmicas internas são coerentes com o contexto social ao qual pertencem. Trata-se de pessoas que se influenciam mutuamente com intensidade (dependência emocional) e respondem a expectativas recíprocas. Em geral eles compartilham significados, valores e crenças que configuram a sua cultura.

Atkinson et al. (1985 apud Cecagno; Souza; Jardim, 2004) $)^{14}$ dizem que a doença interfere nas relações familiares, podendo mexer nos laços afetivos, causando o afastamento da família ou unificando-a, de forma que, mesmo frente a dificuldades vivenciadas, mantém-se a unidade entre seus membros, podendo, inclusive, tornar os laços familiares mais fortes e proporcionar que se estabeleçam novas prioridades para suas vidas.

Através do convívio com os pacientes, os enfermeiros têm a oportunidade de deixá-los se colocarem como pessoas em sua totalidade e não somente como alguém rotulado com câncer. Essa possibilidade assistencial permite tornar seu trabalho mais humanizado e direcionado às necessidades que os pacientes e seus familiares têm durante o transcurso da doença e do tratamento, principalmente no espaço de realização da consulta de enfermagem ${ }^{15}$.

Para Boff $(1999)^{16}$, todos os seres vivos necessitam de cuidado, caso contrário, adoecem e morrem:

Basta citar o exemplo do tucunaré, um de nossos peixes mais apreciados. Pai e mãe têm imenso cuidado em seus filhotes (alevinos). Fazem o ninho escavando um buraco no fundo do rio e circulam sempre ao redor para protegê-los. Quando ensaiam sair do ninho, os acompanham com cuidado e os alertam contra a dispersão. Ao mínimo risco os filhotes voltam todos juntos ao ninho guiados pelos pais. Os retardatários são recolhidos cuidadosamente dentro da boca dos pais e devolvidos ao grupo ${ }^{16}$. 
De acordo com Teixeira ${ }^{17}$, "a representação do cuidado sinaliza a dependência do outro, pois somos seres dependentes desde que nascemos" e à medida que nos tornamos frágeis e nos aproximamos da doença e da própria morte surge a necessidade de um agente cuidador. Portanto, uma importante função da família é a de oferecer os recursos para manter a saúde e um sistema de apoio nos momentos de crise e nos períodos de doença.

O cuidado é definido como a essência da enfermagem e distinguido em dois tipos: cuidado profissional - aquele prestado pelos enfermeiros, e o não-profissional - aquele cuidado executado pela família, amigos e outros indivíduos. O cuidado tem essencialmente um componente cultural, que precisa valorizar as crenças e valores do homem nas situações de cuidado (Leininger, 1981 apud Crossetti; Arruda; Waldow, 1988) ${ }^{18}$.

Segundo Watson (1991 apud Sales, 1998, p. 309) ${ }^{19}$, o processo de cuidar é esteio que ajuda as pessoas a alcançar (manter) a saúde ou morrer em situação de paz. Assim, entendo o cuidar como forma de amor, um amor dirigido ao outro, onde o encontro humano é, a priori, um problema de ser, sendo o crescimento incentivado através do diálogo afetivo e de um relacionamento harmônico.

O objetivo do cuidar na enfermagem é compreender que o cuidado é dispensado a pessoas que são seres que vivem e crescem através do cuidado e que aprenderam a amar e serem amados desde o seu nascimento. A experiência do cuidado é um processo recíproco e requer o conhecimento de ambas as pessoas que estão envolvidas no cuidado. As pessoas envolvidas precisam perceber o outro em sua totalidade, através de uma relação mútua, na qual a confiança e a coragem são necessárias. Esse processo mútuo é iniciado quando os enfermeiros entram no mundo do outro e o outro os convida para sua vida, e seus sentimentos mais íntimos ${ }^{20}$.

A esse respeito, Teixeira $(2001)^{17}$ ressalta que: lidar com as emoçōes implica ter sensibilidade, saber ouvir e ter uma percepção que vai além da formalidade. É importante saber ler a emoção nas expressões dos sujeitos, nos atos e no tom de voz. Não perceber por perceber, mas a sensibilidade de entender o não-dito, de captar as dimensões, por vezes inconscientes, que o sujeito traz em seu discurso, que fala de suas vivências, de suas sensações corporais. Além do mais, é importante que nos conheçamos e que saibamos expressar nossos sentimentos de modo construtivo, pois o indivíduo que desconhece suas próprias emoções dificilmente perceberá as emoçôes do outro.

A família tem papel fundamental no estabelecimento e na manutenção da saúde do indivíduo doente, portanto, deve ser considerada foco de cuidado para enfermeiros e demais profissionais da saúde. A família enquanto unidade de cuidado e participante ativa no processo saúde-doença de seus membros também deve ser assistida de forma especial pela enfermagem, pois, segundo Chapman (1983 apud CROSSETTI; ARRUDA; WALDOW, 1988) ${ }^{18}$,

o cuidar é a força motivadora importante para as pessoas que escolheram a enfermagem como profissão, pois a enfermagem lhes oferece uma oportunidade de cuidar do outro como poucas disciplinas e deve ser desempenhada com amor e carinho pelos profissionais que a exercem.

De acordo com Santin ${ }^{21}$, "o conforto precisa de uma presença, de um rosto, de sensibilidade e da emoção". É exatamente essa mistura de conforto, cuidado e emoção que deve ser dispensada pelos enfermeiros no desempenho de sua profissão ao cuidar de pessoas no momento do desconforto e da fragilidade causados pela doença.

Os enfermeiros representam a arte de cuidar através das palavras que afirmam o valor e a beleza da vida, como o amor, a estética, a identificação, o envolvimento, a vocação (dom), a transformação, o despertar para a vida e, ainda, a linguagem dos sentidos; para eles são esses fenômenos que compõem a arte de cuidar ${ }^{22}$.

Essa profissão tem suas raízes nas necessidades fundamentais da pessoa humana. Os enfermeiros quando fazem a opção voluntária de cuidar dos outros se entregam nesse encontro vivendo e sentindo o eu do outro. Inevitavelmente, eles entram em contato com o outro, preocupam-se com o doente, que, por sua vez, se sente tocado e mobilizado ${ }^{22}$.

Lowen (1990 apud Gotardo, 2002) ${ }^{22}$ ressalta que do envolvimento surge a transcendência, ou seja, o espírito fica tão carregado que transborda as fronteiras do eu. Quando isso acontece, a sensação que se tem é de que nós não sentimos mais que temos um espírito, mas que somos possuídos por ele. Essa parece ser a grande possibilidade para explicar porque sentimos prazer, satisfação em uma profissão que fica na fronteira da vida e da morte, na qual o corpo pode estar quase sem vida, sem energia, doente, sujo, e, ainda assim, o amor, esse sentimento que motiva e mobiliza está presente.

Os profissionais da saúde precisam saber o porquê da escolha de trabalhar com o paciente com câncer, bem como com seus familiares. É importante responder a essa pergunta, já que isso interfere na maneira como se constrói a relação do enfermeiro com essas pessoas. Apesar de, inicialmente, os enfermeiros responderem que sempre pensaram em trabalhar com saúde e doença, poderiam ter escolhido pediatria, obstetrícia - tantas outras áreas - e conseqüentemente ficariam um pouco 
mais distantes de uma realidade diária que fala de muita dor e de muito sofrimento ${ }^{23}$.

Se há a decisão de cuidar das pessoas, porque se imagina que elas possam ser ajudadas, por respeito ao ser humano e à vida, deve-se agir de forma coerente com a intenção de respeitar a vida - o que envolve reconhecê-las nas suas diferentes formas, aceitar suas inúmeras diferenças e estar atento às suas expressões, entendendo que a verdadeira mensagem das coisas está nas pessoas e não nas palavras. Descobre-se, assim, que cada pessoa é uma história e qual a história que cada um é. Descobre-se isso ouvindo, olhando; ouvindo, tocando; ouvindo ${ }^{23}$.

Os enfermeiros, através do modo de cuidar, propiciam ao outro a percepção de que existe nele uma força, uma pulsão de vida, uma vontade que, quando acionada, é capaz de gerar grandes transformaçôes. Assim, a verdadeira obra de arte da enfermagem está em transformar um ser humano doente em um ser humano com melhor qualidade de vida, reconhecendo no processo de doença uma possibilidade de crescimentos pessoal, social e espiritual ${ }^{22}$.

\section{APRESENTAÇÃO DOS RESULTADOS}

Durante o desenvolvimento desse estudo no setor de quimioterapia do HUAP, diante das falas dos sujeitos, foram observados os sentimentos e reaçōes vivenciadas pelos familiares de pessoas que acompanham o parente em quimioterapia antineoplásica. Assim, ao conhecer um pouco do dia-a-dia dessas pessoas, pôde-se entender que a família e o doente procuravam estreitar os laços de amizade e de aproximação com os profissionais que lá se encontravam. Ademais, compreendeu-se que a família desempenha um papel fundamental no cuidado ao outro, procurando sempre manter acesa a chama da esperança.

Ao olhar e ouvir os familiares no cenário do estudo, foi possível captar e compreender melhor as etapas vivenciadas por eles com seus parentes numa luta contínua contra uma doença que assusta e gera sentimentos de incerteza quanto ao futuro próximo. Viver essa batalha diária implica em buscar forças para apoiar o outro, ainda que, muitas vezes, presenciar a fragilidade do parente frente à doença e ao tratamento, bem como o medo do desconhecido tivessem que ser velados para proporcionar o estímulo que ele precisava naqueles momentos.

A seguir, são apresentados os resultados:

\section{TRATAMENTO QUIMIOTERÁPICO: A NOTÍCIA}

De um modo geral, a reação das pessoas, ao tomarem conhecimento do câncer, é de desespero, pois não é possível prever com exatidão o que irá acontecer.
Esse espanto ainda é maior quando é reportado para dentro da própria família, uma vez que essa unidade social está interligada, tendo como perspectiva natural ver os filhos crescerem e ao mesmo tempo acreditar que sempre serão saudáveis ${ }^{12}$.

O câncer remete ao medo de mutilações e desfiguramento, à perspectiva de tratamentos dolorosos e de muitas perdas provocadas pela doença. Essa situação de sofrimento conduz a uma problemática psíquica com características específicas ${ }^{11}$.

$\mathrm{O}$ ataque indiscriminado promovido pelas drogas antineoplásicas às células de rápida proliferação, cancerosas ou normais, produz os indesejáveis efeitos colaterais ou tóxicos, conhecidos e extremamente temidos pelos indivíduos que necessitam submeter-se ao tratamento. São comuns os tabus, as idéias preconcebidas e os temores que desesperam os pacientes e acabam por afastá-los da possibilidade de cura. Os enfermeiros devem atuar dissipando dúvidas e desfazendo tabus, temores e preconceitos enraizados entre os pacientes e a população em geral ${ }^{10}$.

Diante da agressividade do tratamento e do prognóstico incerto, a família do doente sente-se abatida, buscando apoio na equipe multidisciplinar e, principalmente, na enfermagem que presta assistência contínua ao paciente em tratamento quimioterápico. Para Smeltzer; Bare (2002, p.251): "[...] a enfermeira que lida com câncer deve estar preparada para apoiar o cliente e a família em todas as extensões das crises, seja física, emocional, social, cultural e espiritualmente"7.

A maioria dos familiares entrevistados declarou ter recebido a notícia da quimioterapia como um evento desastroso e triste em suas vidas, freqüentemente relacionado a situações de desespero, com choro, como algo horrível, com o medo ocasionado pelas reaçōes provenientes da quimioterapia (náuseas, vômitos, queda dos cabelos).

Assim... não é bom não, né... a gente vê que eles sofrem com isso e a gente também, eles enjoam, passam muito mal, os cabelos vão caindo...é isso....(João, filho).

É uma situação horrível, né? Você pensa que "isso" vai dar em qualquer pessoa menos na sua família, aí você vê, depois que aparece uma coisa dessa, que sua vida não tinha problema nenhum, esses probleminhas que você tem em casa com filhos que parecem muito grande, depois que aparece um problema desse na sua família você vê que aquilo era uma beleza, que você vivia no paraíso e não sabia, entendeu? Você não tinha problema nenhum, aí aparece um mundo na sua vida totalmente... a gente muda totalmente os valores 
né... depois que começa uma quimioterapia dessa não é só o problema da quimioterapia, o problema é a "cabeça", a pessoa que toma quimioterapia ela entra em "parafuso", incrível, ela se sente... primeiro que os cabelos caem, né, pra mulher, bem eu digo pra mulher porque pra homem nem tanto né, porque eu não sei caso de homem, mas ela como é mulher, só o fato de os cabelos caírem todo, eu sei que deprime muito, ela chorava muito, agora ela tá melhorando mas ela tem crises de depressão, entendeu? Então a vida da gente muda muito, os valores, a rotina da gente muda totalmente, afeta os filhos, afeta a gente, afeta até o trabalho hoje mesmo eu to faltando o trabalho pra tá aqui com ela...(Gabriel, marido).

No começo eu fiquei chocada, porque ela nunca teve problema nenhum, mas Graças a Deus, confiando em Deus, é Ele sobre todas as coisas, né? Tá na mão de Deus. Eu tô confiando em Deus porque pra ela, então, foi um choque muito grande, principalmente porque ela tem um neném de dois anos e ele mamava e quando foi a primeira vez que ela chegou o garotinho queria mamar e não pode por causa da quimioterapia, entâo começou... ela e o neném, todo mundo a chorar, entendeu? Então foi um choque muito grande pra todo mundo dentro de casa... (Graça, mãe).

É inquestionável o reconhecimento de que o diagnóstico do câncer e o tratamento quimioterápico causam um enorme impacto de ordem física e psicológica na vida das pessoas que são submetidas a esse tipo de situação.

O existir do doente com câncer, na maioria das vezes, é marcado por um sofrimento contínuo, que traduz sentimentos diferentes, dependendo dos momentos em que vive e das crises que experiencia. A doença e o tratamento quimioterápico fazem parte do indivíduo e, nessa concepção, é essencial pensar que eles estão enredados no viver de seus familiares ${ }^{19}$.

\section{A QUIMIOTERAPIA: SENTINDO NA PELE}

Devido ao alto índice de estresse que a área oncológica representa, percebe-se que o cuidador, que aqui é representado pela família do doente, experiencia momentos de tristeza, depressão e está sujeito à síndrome da exaustão relatada tantas vezes por especialistas no assunto. $\mathrm{Na}$ encruzilhada dos caminhos entre quem cuida e quem é cuidado, é importante que também se comece a refletir sobre o cuidado dispensado ao cuidador. Como se sente aquele que cuida de outro ser humano e que, muitas vezes, passa pelos mesmos sentimentos de quem está em busca da cura ou que espera a morte? Quem cuida daquele que cuida? ${ }^{24}$
Ao vivenciar a "experiência do câncer", a família enfrenta uma série de sentimentos angustiantes e dolorosos, lidando com o que chamamos de "experiência do adoecer em família", um momento tão difícil para o paciente quanto para a família que passam, juntos, pelos mesmos sentimentos e experienciam o medo e a expectativa da morte, pois cuidar de pessoas que fazem tratamento quimioterápico traz dor e sofrimento, principalmente quando se trata de alguém muito próximo ${ }^{25}$.

E quanto mais a família convive, participa e se envolve com a história do seu parente, mais sofre ao assistir a progressão das espoliaçôes que a doença e o tratamento causam no organismo e na imagem daquela pessoa ${ }^{26}$.

A família é a principal instituição social, na qual o indivíduo inicia suas relações afetivas, cria vínculos e internaliza valores. Essa relação familiar apresenta-se de forma interligada como se fosse a extensão do outro, pois acredita-se que a experiência de uma doença grave traz modificaçôes no modo de pensar, sentir e agir das pessoas $^{12}$.

A maioria dos familiares entrevistados contou que se sentiam muito mal em ver seu parente em quimioterapia antineoplásica e que a quimioterapia é um evento constrangedor, doloroso e que se sentem como se fossem a própria pessoa que está fazendo a quimioterapia.

Eu fico com pena de ver meu pai nessa situação, mas até que, quando ele faz, ele vem animado, não fica muito desanimado não...depois que passam uns dias é que ele fica muito deprimido, fica fraco..., mas quando ele tá aqui fazendo até que ele fica bem (Camila, filha).

É uma coisa muito constrangedora, a gente que nunca passou por isso, né, a gente toma um susto mas hoje... é lógico e evidente que a gente fica com o coração meio partido...(Jorge, pai).

Você pensa que você tá num pesadelo e que vai acordar, aquele pesadelo que você fecha o olho assim e acorda, só que esse não acorda né? Aí é uma situação horrível, você fica apreensivo, fica contando as quimioterapias pra acabar esse tormento logo porque não é problema fazer agora, o problema é quando ela chega em casa começa a passar mal, aí é uma semana sentindo mal, sentindo enjôo, entra em depressão é uma semana horrível...(lágrimas nos olhos) (Gabriel, pai).

O tratamento quimioterápico é identificado pelos familiares como doloroso devido aos efeitos colaterais e também como responsável pela inabilidade física, transformação dos corpos, mudanças na imagem corporal, alteraçóes no cotidiano e emocionais, 
promovendo sentimentos de tristeza, medo, nervosismo, depressão e angústia.

Considerando que o tratamento antineoplásico é rotineiro, fragmentado e regulado pelo compasso temporal que a patologia impóe, o paciente, que está ali para vencer ou controlar o câncer, precisa ser considerado dentro do seu contexto social e em sua singularidade ${ }^{15}$.

Nesse contexto, é importante que os enfermeiros dispensem algum tempo para explicar os efeitos colaterais. As possíveis soluçôes podem aliviar parte da ansiedade das pessoas que, muitas vezes, se sentem desconfortáveis em fazer perguntas. Quanto mais informado estiver o paciente sobre os efeitos colaterais da quimioterapia e sobre como controlá-los, melhor poderão prevê-los e lidar com eles ${ }^{7}$.

\section{A QUIMIOTERAPIA E SEUS HORIZONTES}

A quimioterapia antineoplásica, ou seja, a utilização de agentes químicos, isolados ou em combinação com o objetivo de tratar os tumores malignos, tem se tornado uma das mais importantes e promissoras maneiras de se combater o câncer ${ }^{10}$.

Assim, ela é considerada um avanço na cura e controle do câncer, aumentando a expectativa de vida do paciente. É essencial, no entanto, que os profissionais de saúde que atuam na área de oncologia ofereçam suporte emocional, e efetivas orientações quanto aos objetivos e efeitos colaterais do tratamento quimioterápico?

A quimioterapia representa a possibilidade de continuar vivendo e retomar o cotidiano que foi alterado a partir do diagnóstico do câncer. Porém, apesar de todo o impacto físico e o psicológico, as pessoas consideram que continuar o tratamento é reconhecer que os efeitos colaterais não são duradouros e o que se busca é a recuperação da saúde ${ }^{27}$.

A maioria dos sujeitos disse que espera a cura através do tratamento quimioterápico e vivem na esperança da cura através do mesmo.

Espero que ela esteja curada de verdade mesmo, que não tenha mais nada mesmo... nem que vá pra cirurgia, entendeu? Eu tenho fé em Deus que vai dar isso o resultado... pelo que viram ontem... entendeu... já viram um avanço bem adiantado na "coisa" dela, reduziu... de repente nem vai precisar da cirurgia né... num sei...(Mônica, filha).

Cura, espero a cura, acho que todo mundo espera a cura, né? A dela eu tenho certeza que ela vai ficar curada (Gabriel, marido).

Eu acho que é uma evolução muito grande na medicina porque do jeito que nós vimos a nossa filha e do jeito que a gente vê ela hoje então eu acho que acima de Deus é o medicamento que ela tá fazendo, a quimioterapia tá evoluindo muito bem então isso é um passo muito importante na medicina porque é uma doença que antigamente as pessoas olhavam com morte, 'ah, tá com câncer, vai morrer', então hoje não, hoje Graças a Deus o câncer tem cura, né...(Jorge, pai).

Essas falas nos levam a constatar que cuidar é mais do que um ato; é uma atitude. Portanto, abrange mais do que um momento de atenção, de zelo e de desvelo. Representa uma atitude de ocupação, preocupação, de representação e de envolvimento afetivo com o outro ${ }^{16}$.

Para Boff ${ }^{16}$, o cuidado somente surge quando a existência de alguém tem importância para o outro, é quando, então, passamos a nos dedicar a ele; dispondonos a participar de seu destino, de suas buscas, de seus sofrimentos e de seu sucesso, enfim, de sua vida.

Apesar de conviverem com as restrições impostas pela doença e o tratamento, os doentes buscam formas de enfrentar essas vicissitudes através da consciência de estarem no mundo não como seres doentes, mas sim como seres que lutam pela própria vida ${ }^{28}$.

\section{O CUIDADO QUE ACOLHE 0 OUTRO...}

Acredita-se que o profissional enfermeiro não deva apenas promover a saúde dentro das instituições cuidadoras, mas também procurar compreender os sentimentos enredados no bojo de cada pessoa portadora de uma doença crônica, como o câncer. Cumpre-lhe repensar o cuidado tanto físico quanto psíquico, ou seja, o cuidado integral ao ser doente e seus familiares, encorajando-os a encarar seus problemas e a superar as dificuldades domésticas que são encontradas diante do enfrentamento da doença ${ }^{28}$.

A assistência humanizada aos familiares do paciente com câncer consiste no emprego de atitudes que originem espaços que permitam a todos verbalizar seus sentimentos e a valorizá-los; identificar áreas potencialmente problemáticas; auxiliá-los a identificar fontes de ajuda, que podem estar dentro ou fora da própria família; fornecer informações e esclarecer suas percepçôes; ajudá-los na busca de soluçôes dos problemas relacionados ao tratamento; instrumentalizálos para que tomem decisões sobre o tratamento proposto; e levar ao desempenho de ações de autocuidado, dentro de suas possibilidades.

Provavelmente, a mola mestra, que vai mobilizar toda a assistência emocional que será prestada ao paciente com câncer e sua família, é a forma como a equipe se comunica e interage com eles. Considera-se de grande ajuda a interação multiprofissional, sendo clara a 
possibilidade de visualizar o paciente como um todo, pois o cuidado à saúde transcende o simples ato de assistir centrado no fazer, nas técnicas ou nos procedimentos, significa reconhecer os pacientes e seus familiares como seres humanos singulares, vivenciando um difícil momento de suas vidas ${ }^{29}$.

As pessoas, na maior parte das vezes, necessitam se sentir protegidas, seguras, orientadas e saber que podem contar com alguém para compartilhar a experiência, de forma menos dolorosa e sofrida, e isso é de grande valia.

Para as pessoas entrevistadas, a orientação e o esclarecimento de dúvidas acerca da doença e de seu tratamento, de modo paciente e carinhoso, são considerados elementos fundamentais para ajudar e confortar os pacientes no decorrer da quimioterapia.

Além disso, pôde-se perceber que foi unânime a idéia de que eles se sentem felizes em saber que $o$ atendimento oferecido ao seu parente é permeado de conforto e carinho dos profissionais.

$\mathrm{Eu}$ acho que o importante nesse trabalho e é por isso que eu faço tratamento aqui porque as pessoas que tratam da oncologia são muito mais educadas que nos outros setores. Se reparar a enfermagem é mais educada, trata melhor, é mais carinhosa, então isso é importante. Você vê setores da medicina, da saúde que os funcionários são ignorantes tratam você mal, não dão atenção, então na oncologia eu vi uma realidade diferente, é importante isso, essa realidade é importantíssima. Os médicos são simpáticos, são muito atenciosos, a enfermagem é atenciosa, então todo o sistema que trata da oncologia são carinhosos e atenciosos então eu acho que isso é muito importante pra cabeça de quem tá fazendo quimioterapia (Gabriel, marido).

Olha, eu acho a equipe médica, os enfermeiros, os auxiliares é... acho que eles são guiados por Deus... (choro) eles tão sendo muito importante na vida da minha filha. Eu em toda a minha vida, eu nunca vi uma equipe tão competente, muito competente, eles tão salvando a vida da minha filha. Eles são bons, atenciosos com ela....(Jorge, pai).

No meu modo de ver, eles tão fazendo o melhor possível, são muito bons, são carinhosos, trata eu muito bem, trata ele muito bem, com respeito, com carinho, com ele mais ainda...hi aqui tinha uma enfermeira que eu vou te contar, aquela tinha uma luz como essas pessoas que tão aí dentro, ela traz muita paz, muita luz, no momento que a gente chegava aqui e via ela, pronto! $\mathrm{O}$ coração da gente se tivesse apavorado, se acalmava...(Nilzeti, esposa).

A essência dessa profissão é o cuidado, sendo este o verdadeiro instrumento dos profissionais enfermeiros.
O cuidar vai além de executar técnicas: ele envolve presença, confiança e atitude do profissional enfermeiro com o paciente que está sendo cuidado pela sua família. Nesse sentido, para cuidar, é preciso, em muitos momentos, colocar-se no lugar do outro e perceber, mesmo na linguagem não-verbal, as necessidades fisiológicas e emocionais, proporcionando ao outro conforto e segurança, para que ele possa conviver melhor com os momentos difíceis, de forma mais amena e tranqüila $^{28}$.

Assim, o grande desafio dessa nossa profissão é fazer do discurso sobre o cuidado a essência das nossas açōes com o outro e isso inclui despir-se de pré-concepçôes que isolam e fragmentam o paciente da sua família. Cuidar é ter como meta a recuperação, prevenção, manutenção e promoção da saúde do indivíduo em sua integralidade e singularidade.

\section{CONSIDERAÇÕES FINAIS}

Este estudo possibilitou a seguinte compreensão: a doença não só envolve a pessoa doente, mas todo o grupo familiar, que apóiam-se mutuamente e buscam valorizar um modo de agir, no qual o estar perto, o estar junto, o estar presente com o familiar doente é de grande relevância no momento do tratamento de quimioterapia antineoplásica e durante todo o processo de cura e recuperação do doente. Assim, os objetivos almejados através do estudo puderam ser contemplados, deixando sempre clara a importância da atuação do enfermeiro junto à família do paciente em quimioterapia antineoplásica.

A família é permeada por uma diversidade de sentimentos na convivência com o paciente com câncer, por isso é necessário que se reconheça que tanto familiares quanto doentes estão sujeitos a passarem pelos mesmos sentimentos como, por exemplo, o medo da quimioterapia e dos efeitos colaterais da mesma, o medo da cirurgia, enfim, o medo do desconhecido e a sensação de impotência diante da situação.

À medida que a pesquisa foi chegando ao final, pôdese compreender o modo de agir, pensar e sentir de cada familiar e, também, compreender que o "universo" de todos os que têm ou tiveram um parente com câncer é muito singular, e que o conforto de uma mão amiga, o carinho, uma palavra de incentivo fazem toda a diferença quando se procura, de todas as formas, ter de volta a pessoa que se ama. Muitas vezes, a sensação que se tem é de que a pessoa a qual amamos está indo embora quando descobrimos a doença e o tratamento a ser seguido, talvez tudo isso ocorra pela mudança na vida das pessoas, pela mudança da rotina e até mesmo pela mudança física ocasionada pelo tratamento quimioterápico que, 
geralmente, vem junto com a queda dos cabelos, o corpo cansado e a magreza que não dá para esconder.

A experiência junto aos familiares de pessoas em quimioterapia antineoplásica veio reforçar a idéia de que a família precisa ser valorizada e estimulada a participar do cuidado de seus membros, fazendo com que o cuidado torne-se mais efetivo e o paciente possa responder melhor à terapêutica utilizada.

Espera-se que este estudo seja o início de novos questionamentos e concepçóes para enfermeiros e demais profissionais da área da saúde, fazendo com que os mesmos reflitam sobre a importância da família, levando em consideração que não só o doente, mas também a família necessitam ser cuidados e assistidos em suas necessidades emocionais e individuais e, ainda, que este trabalho proporcione um melhor entendimento sobre os sentimentos e as reações da família que cuida e acompanha o doente em tratamento de quimioterapia antineoplásica, favorecendo, dessa forma, a reflexão dos profissionais sobre a importância de humanizar a assistência ao doente e seus familiares.

\section{Potencial conflito de interesses:}

Os autores declaram não haver conflito de interesses.

\section{REFERÊNCIAS}

1. Gonzalez H. Enfermagem em oncologia. São Paulo: SENAC; 1994.

2. Bielemann VLM. A família cuidando do ser humano com câncer e sentindo a experiência. Rev Bras Enferm. 2003;56(2):133-37.

3. Ferreira SS, Neves HP. Ser enfermeira vivenciando o cuidado ao cliente com câncer em tratamento quimioterápico. Rev Técnica e Científica de Enferm. (Curitiba). 2003;1(1):49-54.

4. Minayo MCS. Pesquisa social: teoria, método e criatividade. Rio de Janeiro: Vozes; 1994.

5. Minayo MCS. O desafio do conhecimento: pesquisa qualitativa em saúde. 3a ed. São Paulo: Vozes; 2002.

6. Bergamasco RB, Gualda DMR. Modelos teóricos de doença crônica. In: Bergamasco RB, Gualda DMR. Enfermagem, cultura e processo saúde-doença. São Paulo: Ícone; 2004:39-48.

7. Smeltzer SC, Bare BG. Brunner \& Suddarth. Tratado de enfermagem médico-cirúrgica. 9a ed. Rio de Janeiro: Guanabara-Koogan; 2002.

8. Lima RAG. A enfermagem na assistência à criança com câncer. Goiânia: AB; 1995.

9. Melo EM, Araújo TL, Oliveira TC, Almeida DT. Mulher mastectomizada em tratamento quimioterápico: um estudo dos comportamentos na perspectiva do modelo adaptativo de Roy. Rev Bras Cancerol. 2002;48(1):21-28.
10. Bonassa EMA. Enfermagem em quimioterapia. São Paulo: Atheneu; 1998.

11. Carvalho MM. Psico-oncologia: história, características e desafios. Psicol USP (São Paulo). 2002;13(1):1-14.

12. Araújo JS, Nascimento MAA. Atuação da família frente ao processo saúde: doença de um familiar com câncer de mama. Rev Bras Enferm. 2004;57(3):274-78.

13. Pedrolo FT, Zago MMF. O enfrentamento dos familiares à imagem corporal alterada do laringectomizado. Rev Bras Cancerol. 2002;48(1):21-28.

14. Cecagno S, Souza MD, Jardin VMR. Compreendendo o contexto familiar no processo saúde-doença. Acta Scientarum - Health Sciences (Maringá). 2004;26(1):10712. [acesso em 16 set 2005]. Disponível em: <http:// www.ppg.uem.br/Docs/cof/Saude/2004_1/13_181>

15. Alcântara LFFL, Malveira EAP, Becque GV. Enfermeiras cuidando em oncologia ambulatorial: a consulta de enfermagem e o sentido de cuidar. Rev Enferm UERJ. 2004;12(3):159-64.

16. Boff L. Saber cuidar. Ética do humano-compaixão pela terra. 11 a ed. Petrópolis: Vozes; 1999.

17. Teixeira ER, Figueiredo NMA. O desejo e a necessidade no cuidado com corpo: uma perspectiva estética na prática de enfermagem. Niterói: EDUFF; 2001.

18. Crossetti MGO, Arruda EN, Waldow VR. Elementos do cuidar/cuidado na perspectiva de enfermeiras de um município gaúcho. Texto Contexto-Enfermagem (Florianópolis). 1998;7(2):133-50.

19. Sales CA. O cotidiano do enfermeiro e seu cuidado ao ser leucêmico. Texto Contexto-Enfermagem (Florianópolis). 1998;7(2):308-19.

20. Boykin A. A enfermagem como conforto: o artístico no cuidado. Texto Contexto-Enfermagem (Florianópolis). 1998;7(2):36-51.

21. Santin S. Cuidado e/ou conforto: um paradigma para a enfermagem. Desenvolvido segundo o costume dos filósofos. Texto Contexto-Enfermagem (Florianópolis). 1998;7(2):111-32.

22. Gotardo GIB. Nos bastidores da enfermagem: a arte de cuidar como essência. Rev Enferm UERJ. 2002;10(2):146-49.

23. Silva MJP. Qual a mensagem que quero transmitir quando cuido? Rev Soc Bras Cancerol. 1999;8. [acesso em 12 set 2005]. Disponível em: <http://www.rsbcancer.com.br/ rsbc/8suplemento.asp?>

24. Souza AIJ, Radünz V. Cuidando e confortando o cuidador. Texto e Contexto-Enfermagem (Florianópolis). 1998;7(2):180-94.

25. Bielemann VLM A família cuidando do ser humano com câncer e sentindo a experiência. Rev Bras Enferm. 2003;56(2):133-37.

26. Ferreira SS, Neves HP. Ser enfermeira vivenciando o 
cuidado ao cliente com câncer em tratamento quimioterápico. Rev Técnica e Científica de Enferm. (Curitiba). 2003;1(1):49-54.

27. Jesus LLC, Lopes RLM. Considerando o câncer de mama e a quimioterapia na vida da mulher. Rev Enferm. UERJ. 2003;11(2):208-10.
28. Sales CA, Molina MA. O significado do câncer no cotidiano de mulheres em tratamento quimioterápico. Rev Bras Enferm. 2004;57(6):720-23.

29. Costa CA, Lunardi Filho WD, Soares NV. Assistência humanizada ao cliente oncológico: reflexōes junto à equipe. Rev Bras Enferm. 2003;56(3):310-14.

\section{Abstract}

The objectives of this qualitative study were to describe the family's feelings and reactions towards relatives undergoing cancer chemotherapy, to identify the family's expectations when accompanying the patient, and to discuss the possibilities for nurses to work with family members. The information-gathering process included simple observation and semi-structured interviews with family members of ten patients undergoing cancer chemotherapy. We conclude that the family's experience is permeated with difficult moments and that both the cancer and its treatment involve not only the patient, but also the entire family group, consistently showing its willingness to help the patient deal with the disease. Thus, assistance by the nurse and multidisciplinary team is essential to provide support for patients and family members in order to improve their quality of life.

Key words: Neoplasm, Chemotherapy, Family, Nursing care 
